\title{
Culinary tourism in Egypt: a tourist perspective
}

\author{
Mona Abdelbadie Elmoghazy and Maii Baher Omar \\ Department of Tourism Studies, Faculty of Tourism and Hotels, Helwan University
}

\begin{abstract}
Over the past few years, culinary tourism has gained increasing importance in tourism industry. This relatively new market offers destinations numerous marketing opportunities. However, investigating culinary experience and its effect on tourist satisfaction and perception of a destination is under researched. The current study aims to assess Egyptian local food image attributes and its potential impact on both tourist food experience satisfaction and revisit intentions. For this purpose, self-administered questionnaires were distributed to a sample of (418) international tourists. Results revealed that there is a relatively high acceptance among tourists that "Egyptian food attributes" dimension is the main image of Egyptian local food. Regression analysis indicated that "food environment" dimension is an important food image that affects tourist's overall satisfaction. Given that there is no specific scale developed for this purpose in Egypt, the main implication of the current study is to provide a measurement scale built on previous research that identifies and assesses attributes of local cuisine from tourist's viewpoint. The current study offers valuable implications as well for destination marketers, managers and businesses that would help them develop and market a new type of tourist attraction and offer unique and memorable culinary experience.
\end{abstract}

\section{Key words}

Culinary tourism, tourist satisfaction, revisit intentions, culinary tourist, Egyptian cuisine.

\section{Introduction}

Food is becoming a main part of experiencing a destination's culture and history. Currently, tourists regard local food as their gateway to well understand a destination's invisible heritage and social environment (LópezGuzmán and Sánchez-Cañizares, 2012; Updhyay and Sharma, 2014).Despite the fact that culinary tourism is not a new travel activity, it witnessed a 
remarkable growth during the last few years (Ottenbacher and Harrington, 2013), and became a major feature of tourism industry that grabbed the attention of international tourists (Horng and Tsai, 2010; Horng and Tsai, 2012; Horng et al., 2012) who are increasingly interested in visiting a destination to experience its local cuisine ( Ottenbacher and Harrington, 2013; Smith and Costello, 2009).

In response, destinations began to compete in the dishes they serve as well as in their different natural and historical resources (Surenkok et al., 2010). No wonder, they are increasingly improving culinary travel markets and making necessary adjustments to their culinary tourism strategies to compete effectively with other well-known culinary travel destinations (Horng and Tsai, 2012).

As a result, DMOs (Destination Marketing Organizations) had lately taken necessary arrangements in destinations to gain a competitive edge through refeaturing their cuisine so as to link tourists with local culture and tradition and provide them with unforgettable experience on the one hand (Hjalagr and Richards, 2002, Jalis et al., 2014) and build a destination image resting on its unique cultural resources and its culinary products while on the other hand. (Hall and Mitchell, 2005).

Although Egypt has all potentials to be a prospect culinary tourism destination depending on its rich culture and history, there is a clear absence of studies investigating culinary tourism in Egypt with respect to international tourists at a time where worldwide destinations are taking the advantage of the relatively new promising travel activity to promote their heritage. Thus, there is a limited understanding of how foreign tourists view Egyptian cuisine.

Therefore, this research aims at investigating international tourists' perception of Egypt as a culinary destination, and assessing their overall satisfaction and how it may affect their future intentions in a way or another.

On the other hand, the present research fills part of the gap in culinary tourism research in Egypt and presents diverse features and valued dimensions that marketers, practitioners and researchers could use to position Egypt in a way that attract culinary tourists, meet this relatively new market segment of travelers 'needs and grant them a pleasant experience.

\section{Literature Review}

\section{Linkage between food and tourism}

There is a strong relationship between food and tourism, literature in the field addresses this relationship in four main distinct areas: first, food as a standalone attraction that is used in marketing the destination. Second, food as a part of the tourism product. Third, food as a tourist experience where 
determinants affecting overall evaluation and satisfaction are taken into consideration. Fourth, as a part of destination cultural heritage which is related to tourists whose prime concern in visiting a destination is tasting local cuisine, attending festivals or other activities that are closely linked to food often referred to as "culinary tourism" (Ab Karim et al., 2009; Cerovic, 2003; Mak et al., 2012a; Peštek and C ${ }^{`}$ injarevic, 2014; Sanchez-Cañizares and Castillo-Canalejo, 2015; Sotiriadis, 2015).

The term "culinary tourism" was first presented by Lucy Long in 1999 (Wolf et al., 2014) to clarify that tasting a region's food and wine helps in deep and better understanding its culture.

Culinary tourism can be defined as "the international, exploratory participation in the foodways of an other. Participation includes the consumption, preparation, and preservation of a food item, cuisine, meal system, or eating style considered to belong to a culinary system no one's own" (Long, 2004:20-21). The term "foodways" proposes that food includes a number of physical, social, cultural, economic, spiritual and aesthetic activities (Long, 2004).

According to Long (2004) participation in foodways involves preparation and preservation of food, menu planning, dishes presentation, eating styles and cooking techniques, "food ethos" and food consumption. Thus, tourists can successfully establish their own unique experiences trough preparing, presenting and consuming food.

In the same vein, Ignatov and Smith (2006:238) proposed a different definition to culinary tourism, "trips during which the purchase or consumption of regional foods (including beverages), or the observation and study of food production (from agriculture to cooking schools), represent a significant motivation or activity".

Recently, Wolf (2014:12) presented a new definition of culinary tourism as "the pursuit and enjoyment of unique and memorable food and drink experiences, both far and near". Wolf clarified "far and near" as food travelers who travel across country or the world as well as those who travel in the regions, towns and neighborhoods where they live (Wolf et al., 2014).

Culinary tourism is also defined as "visitation to primary and secondary food producers, food festivals, restaurants, and special locations for which food tasting and/or experiencing the attributes for specialist food production as the primary motivation for travel" (Hall and Mitchell, 2001: 308; Hall and Sharples, 2003: 10).

For Smith and Costello (2009: 99), culinary tourism "promotes visitor attractions with unique and memorable food and drink experiences". 
A review of tourism literature reveals that existing studies in culinary tourism are mainly related to the following areas as summarized in table (1).

Table (1): Main studies of culinary tourism in literature

Topic Authors

culinary tourism and tourist experience

food as a form of destination

identity

potentials of culinary tourism as a

powerful tool in promoting

destinations

culinary tourism strategic

development and strategic

planning

assessing satisfaction at a

culinary event

determinants of brand equity and

the role of destination familiarity

for travel intentions in culinary

tourism from the perspective of

foreign tourists

factors influencing consumption

of local food and beverages in

destinations

examining the interesting

mobilities that are involved in

Ab Karim et al., 2009; Sanchez-Cañizares and Castillo-

Canalejo, 2015;Chang et al., 2010; Cohen and Avieli, 2004;

Kivela and crotts, 2006; Kivela and crotts, 2009; Lin, 2014;

López-Guzmán and Sánchez-Cañizares, 2012; Mkono,

2011; Pes `tek and C`injarevic, 2014; Smith and Xiao, 2008;

Surenkok et al., 2010; Updhyay and Sharma, 2014

Lin et al., 2011

Chaney and Ryan, 2012; Ottenbacher and Harrington, 2013

Horng and Tsai, 2012; Obonyo et al., 2012; Sotiriadis, 2015

Mason and Paggiaro, 2012; Smith and Costello, 2009

Horng et al., 2012; Lin, 2009; Sparks, 2007

Kim et al., 2009; Kim and Eves, 2012; Kim et al., 2013 Mak

et al., 2012b

Molz', 2007 
culinary tourism

globalization and food

consumption in tourism

Government websites for

promoting a tourist destination's

exciting cuisine and food culture

culinary tourists
Mak et al., 2012b

Horng and Tsai, 2010
Ignatov and Smith, 2006; Robinson and Getz, 2014; Yuan, 2013; Yun et al., 2011

All of these studies -among others- support the significant role of food in enhancing tourist experience, promoting, branding and developing destinations and not merely a source of nourishment. It worth to mention that culinary tourism is considered a successful tourism activity in destinations whose local food is closely linked to their local culture (Ignatov and Smith, 2006) particularly with regard to changes in tourists' preferences which affected significantly the way they conceive local food in their travel experience; they are paying more attention toward local food, good taste, and quality service alike( Surenkok et al., 2010).

Therefore, culinary tourism promotes self-recognition via experiencing the destination food which differs largely from just consuming food as in habitual travels. Enjoyable narratives, special knowledge and information of local cuisine that represent local culture and identity can be conveyed through culinary tourism (Horng and Tsai, 2012).

As such, special cuisine can make a popular culinary destination, enhance its culinary image, and make its culinary culture a main attraction if well developed, promoted and marketed (Horng and Tsai, 2010; Horng and Tsai, 2012).

\section{Culinary tourism and destination marketing}

As culinary tourism grows rapidly with a similar growth in interests in local food, it has been perceived as an effective tool used for boosting tourism at certain destinations as well as enhancing a destination's identity, and differentiating and promoting specific destinations in front of other 
competing destinations (Frochot, 2003; Hjalager and Richards, 2002; Horng and $\mathrm{Hu}, 2009$; Horng and Tsai, 2010). Furthermore, local food plays a pivotal role in marketing and branding certain destinations (Cohen and Avieli, 2004; Frochot, 2003; Lin, 2009) Since it is considered a fundamental culture component a destination has to offer (Mak et al., 2012a).

Serious attention has been given by destinations' marketers and governments to reflecting local cuisine considering it an important market niche and a "pull factor" alike in promoting a destination and at the same time a key component of its intangible heritage (Horng and Tsai, 2012).

On the other hand many tourists consider experiencing local knowledge, culture and food the most attractive side of their travel experience as it induces consciousness of the visited region yet inspirits local community to preserve their culture and identity (Hall et al., 2003).

There are a growing number of tourist destinations which are highly regarded due to their unique gastronomy; these destinations are referred to as "foodie" holiday destinations for which gastronomy and activities associated with food are considered a major aspect of the tourist attraction (Kivela and Crotts, 2009).

For those countries whose cuisines are not the main attraction or they do not have obvious culinary identity, there is a growing interest to develop culinary tourism markets, promote culinary tourism, and enhance planning of their culinary strategies to compete with well-known culinary travel destinations (Horng and Tsai, 2012; Ottenbacher and Harrington, 2013). However, adding new services, creating culinary tourism resources is a prerequisite for culinary tourism to survive in a highly competitive marketplace (LópezGuzmán and Sánchez-Cañizares, 2012). In this respect, a travel destination should first define its available culinary tourism resources and uniqueness to identify competitive advantage of its resources and potential developments to promote culinary tourism. In this concern, Ignatov and Smith (2006) and Smith and Xiao (2008) identified culinary tourism resources as facilities, activities, events, and organizations.

Since culinary tourists seek different culinary experiences, marketers should follow different communication processes, offer different programs, and introduce different development strategies to meet various culinary tourists' needs and expectations (Ignatov and Smith, 2006).

\section{Culinary tourists}

New eating experiences are considered to be a major element attracting tourists to a destination (Lin, 2009). Tourists on a trip are often keen to live new experiences; they are motivated to try new and unfamiliar food (Cohen and Avieli, 2004), they consider tasting local food an important link to host 
community’s culture (Lin, 2009; López-Guzmán and Sánchez-Cañizares, 2012).

A number of studies indicate that tourists are concerned with what they eat during their vacation or take travel decisions depending on how they perceive food in the travel destination ( Surenkok et al., 2010). Furthermore, their preferences and interests in a destination's cuisine may have considerable impact on destination choice (Mak et al., 2012a).

In the same vein, Ottenbacher and Harrington (2013) point out that culinary tourists usually search for "new restaurants, local tastes and unique food experiences".

Food consumption may have significant consequences regarding tourists' behavior, it may affect their satisfaction and revisit intentions, and it offers them likewise memorable experiences, for instance "excitement, inspiration and cultural exploration" (Updhyay and Sharma, 2014).

On the other hand, much of tourists' expenditures are on food (Hjalager \& Richards, 2002; Surenkok et al., 2010), and sometimes constitute up to one third of their total expenditure. Therefore, it represents a large part of tourism income (Mak et al., 2012a).This implies that measuring tourist perception of local food in a destination is of a great importance to take necessary decisions regarding product design, food and service quality, and marketing strategies (Horng et al., 2012; Updhyay and Sharma, 2014).

Attempts have been made to classify culinary tourists; Hjalager (2003) proposed a model of culinary tourism experiences, in which culinary tourists are divided into four categories according to their attitudes and preferences for food and eating namely recreational, existential, diversionary and experimental.

While Ignatov and Smith (2006) classified Canadian culinary tourists according to activities and motivations into three major sub-markets that are: food tourists, wine tourists, and food and wine tourists.

For Mack et al., (2009) tourists are divided into culinary tourists and nonculinary tourists, then they classified culinary tourists into two groups "innovators and non-innovators".

Yun et al., (2011) suggested two main approaches to categorize culinary tourists, in the first approach culinary tourists are divided into four categories "deliberate, opportunistic, accidential, and uninterested tourists" based on their culinary experiences and activities linked to food. The second approach classified culinary tourists into three groups: culinary-balanced, culinaryoriented, and familiarity-oriented tourists based on the attitude towards foodrelated behaviors. 
In a recent study, Yuan (2013) offered a different classification for culinary tourists' lifestyles and values namely: idealist, achiever, explorer, belonger and innovator in terms of three primary motivations such as ideals, achievements and self-expression including culinary tourists' activities and demographic characteristics.

\section{Egyptian cuisine}

There is evidence thousands of years ago that ancient Egyptians paid considerable attention to food. Carvings and paintings on tombs and temples portrayed great feasts and different types of food which modern Egyptians still consume. Ancient Egyptians used different methods of cooking; they used grilling, boiling, stewing and roasting. They discovered the art of brewing. Moreover, they gave particular attention to the selection and preparation of food as well as using means of preserving and storing, for instance, salting, smoking and drying; they prepared fish through cleaning fish, covering them with salt, then drying fish through exposing them to the sun, This dish is called Fesieekh which is considered a popular meal for Egyptians till now (El-Hamamsy and Pateman, 2003; El-Hebeishy, 2010; Hosking, 2006; Rishi, 2012; Wilson, 1988). Furthermore, local taste for sweet dishes and for spices in the Middle East was inherited from ancient Egypt and the Greco-Roman world (Roden, 2000).

It is obvious that Egyptian cuisine has been influenced throughout history by other cuisines specifically the Romans, and Ottomans. Egyptian cuisine has been affected as well by other foreign rulers. However, Egypt cuisine remains unique (El-Hamamsy and Pateman, 2003).

Roden (2000) described Egypt's food -since it is one of the Middle East countries- as it has a unique character; it is highly spiced food, presentation is appealing, flavor is distinctive, varied and numerous aromatics are added to dishes with tiny amounts mixed with distinctive spices and herbs. There is social character of cooking and eating activities, it reflects local culture and tradition; hospitality, friendliness, exhilaration and offering large quantities of food to indicate guest's importance are all highly appreciated concepts in local culture. Roden goes further to confirm the existence of "language of food and code of etiquette for serving and presenting" (Roden, 2000: 33).

Egypt has a variety of local dishes, Ful Medames is one of the most popular dishes, it worth to mention that beans is the base of other Egyptian dishes particularly Besara and Ta'meyya which was first generated in Egypt, then it spread to several parts of the Middle East. Molokhiyya (a spinach-like vegetable) is another local dish. Koushari (a mixture of lentils, macaroni, rice 
and Chickpeas) is a national food for the masses (El-Hebeishy, 2010). Feseekh (salted, dried fish) is a local dish usually eaten during spring festival of Sham El Nessim which means "breathe the air", it is a festival dating back to ancient Egyptians more than 4500 years ago. Mahshi is considered a Turkish inherited dish.

There are many popular local desserts in Egypt, Basbousa, Baklava, Eish elSaraya, Kahk which is a national sweet dish usually consumed during Eid Ul Fitr, Luqmat al-Qadi, Umm Ali; it is a raisin cake soaked in milk, it is named after the wife of one Mamluk ruler (El-Hamamsy and Pateman, 2003; ElHebeishy, 2010).

There are several traditional drinks; Karkadeh is a local drink which was considered a preferred drink of the Pharaoh, Sugar cane juice named Asser Asab, is a national drink served at nearly all fruit juice shops. Carob (Kharoub) and Tamarind (Tamr Hindi) are also traditional drinks famed for their health benefits (El-Hebeishy, 2010).

On the other hand, there are several culinary training centers and culinary schools in Egypt designing cooking classes and teaching culinary arts and cooking methods that can be used in developing culinary products in Egypt.

\section{RESEARCH METHODOLOGY}

\section{Data collection and survey instrument}

To achieve the study objectives, a descriptive research design was employed that applied quantitative technique for data collection and analysis. A preliminary list of measurement items was developed based on in-depth review of relevant literature pertaining to culinary tourism (Ab Karim et al., 2009; Horng et al., 2012; Pes tek and C`injarevic, 2014; Kim and Eve, 2013; Kivela and Crotts, 2006; Mark et al. 2012a). To refine the measurement scale, first, three academic experts in tourism and hospitality industry were asked to verify the content validity of the preliminary generated items, minor revisions were made based on their suggestions. Second, a pilot study was conducted to ensure each construct's reliability using a convenience sampling of international tourists visiting Egypt $(n=52)$. Minor changes were made to the wording of some items. The 29-items scale consists of three dimensions: Egypt's local food image, tourist satisfaction with local food experience and revisit intentions. The responses were measured using a five point likert-type scale, where 1- strongly disagree and 5- strongly agree. Respondents were approached via convenient sampling at Cairo International Airport before their departure. Three trained researchers introduced themselves and the study to tourists and asked each individual tourist to fill out the questionnaire. The instrument was written in English. About 600 self-administered 
questionnaires were distributed between Oct. 2013 and Feb. 2014. Four hundred eighteen usable questionnaires were retuned representing $69.7 \%$ response rate.

\section{Data analysis}

Data collected in the survey were analyzed using the statistical package for the social sciences (SPSS) version 20.00. Data analysis of the study consists of three steps. First, descriptive analysis was performed to profile tourists in terms of their gender, age, marital status, education level, household income and nationality. Second, an exploratory factor analysis (EFA) with Varimax rotation was used on the data gathered to identify the dimensions of the scale and correlated variables. Reliability alphas within each factor were calculated to confirm the factors' internal consistency. Third, multiple regression analysis and simple regression analysis were applied to determine relationships between tourist perceived image of local food and their satisfaction, as well as relationship between tourist's satisfaction and revisit intentions.

\section{Results}

\section{Descriptive analysis}

Of the 418 respondents, 273 were males $(65.3 \%)$ and 145 were females (34.7\%). The majority of respondents were between $50-59$ years old $(27.5 \%)$ followed by those between $40-49$ years old $(25.1 \%)$. Of all respondents, $(65.6 \%)$ were married. The majority had relatively high educational level, $(89.5 \%)$ were highly educated. The monthly income for most of the respondents was $100.000 \$$ or more $(36.4 \%)$. There were different nationalities amongst the respondents, there was a slightly higher proportion of American and German respondents compared to other nationalities, (21\%) of respondents were Americans, and (10.8\%) were Germans, the rest of the respondents represented other nationalities

\section{Inherent dimensions of Egyptian food image: Factor Analysis}

The 15 items used to measure tourist's perceived image of Egyptian food were exposed to factor analysis to create correlated variables and reduce them into a smaller number of factors that explain most of the variances among attributes. Factor analysis of the Egyptian food image showed that Bartlett's Test of Sphericity was significant $(\mathrm{p}<0.00)$ and KMO measure of sampling adequacy was 0.908 which is above the recommended level (minimum value 0.60) (Hair et al., 2006), indicating that data was appropriate for factor analysis. A Principal Component Analysis with Varimax rotation was used to explore the basic attributes featuring perceived image of Egyptian cuisine. A number of criteria were used to determine the number of factors extracted such as eigenvalue, scree plot, and percentage of variance, item communalities and factor loadings (Hair et al., 2006). only factors with 
eigenvalue greater than or equal to 1.0 were considered, scree plots were also examined, items were retained if they load at 0.4 or more on a factor and did not load at more than 0.3 on any other factor. Only one item was removed as it failed to load at 0.400 or above on any factor. The remaining 14 items were rerun and a three-factor structure emerged again with items clearly loading on their factors at 0.400 or above (Nunnally and Bernstein, 1994).

Fourteen variables across three factors that were retained explain 54.9 of the total variance (table 2). The communalities of 14 attributes ranged from 0.348 to 0.681 indicating that each original variable's variance can be explained (from 35 to 68 percent) by three extracted factors. The internal reliability of each factor was measured by Cronbach's alpha. A Cronbach reliability score, greater than 0.7 refers that the items showed correlation with their factor groupings and can be considered as internally consistent and stable (Hair et al., 2006). The three factors were named based on the items that loaded heavily on them: factor one with six items concerned with "Egyptian food attributes" $(\alpha=0.824)$, factor two includes five items associated with "food environment" $(\alpha=0.809)$, factor three is made up of three items and is concerned with "accessibility" $(\alpha=0.723)$

Referring to the mean scores of the three factors, it's clear that "Egyptian food attributes" had the highest mean score $\chi=3.7$, which indicates a relatively high acceptance among tourists that this factor is an image of the Egyptian food, specifically, the friendly atmosphere (03.92) and good value for money (03.88). This is followed by the image of "food environment" which had a mean score of 3.5 . However, "accessibility" had a relatively lower mean score of 3.4 with reference to factor $1 \& 2$ particularly, the diversity of information on local food (03.21).

Table (2): Results of Factor analysis of Egyptian food image

\begin{tabular}{|c|c|c|c|c|c|}
\hline Dimensions & Mean & $\begin{array}{l}\text { Factor } \\
\text { Loadings }\end{array}$ & $\begin{array}{l}\text { Eigen } \\
\text { Value }\end{array}$ & $\begin{array}{l}\text { Variance } \\
\text { explained }\end{array}$ & Alpha \\
\hline Egyptian food attributes & 3.7 & & 5.518 & 22.092 & 0.824 \\
\hline $\begin{array}{l}\text { Egyptian food is overall } \\
\text { good value for money }\end{array}$ & 3.88 & 0.738 & & & \\
\hline Egypt offers tasty food & 3.80 & 0.703 & & & \\
\hline $\begin{array}{l}\text { Egyptian food adds to my } \\
\text { visiting enjoyment }\end{array}$ & 3.67 & 0.649 & & & \\
\hline $\begin{array}{l}\text { Egyptian food is unique and } \\
\text { original }\end{array}$ & 3.62 & 0.607 & & & \\
\hline The atmosphere is friendly & 3.92 & 0.550 & & & \\
\hline Egypt's food is diverse & 3.64 & 0.487 & & & \\
\hline food environment & 3.5 & & 1.111 & 21.626 & 0.809 \\
\hline $\begin{array}{l}\text { Egypt's food service is high } \\
\text { quality }\end{array}$ & 3.52 & 0.763 & & & \\
\hline
\end{tabular}




\begin{tabular}{|c|c|c|c|c|c|}
\hline $\begin{array}{l}\text { Egypt's food appearance is } \\
\text { good }\end{array}$ & 3.62 & 0.662 & & & \\
\hline Egyptian food is clean & 3.49 & 0.658 & & & \\
\hline $\begin{array}{l}\text { The eating surroundings are } \\
\text { attractive }\end{array}$ & 3.46 & 0.591 & & & \\
\hline Egyptian food is nutritious & 3.62 & 0.545 & & & \\
\hline accessibility & 3.4 & & 1.052 & 11.142 & 0.723 \\
\hline $\begin{array}{l}\text { information on local food is } \\
\text { diverse }\end{array}$ & 3.21 & 0.691 & & & \\
\hline $\begin{array}{l}\text { There are a variety of ethnic } \\
\text { foods }\end{array}$ & 3.50 & 0.631 & & & \\
\hline Eating places are accessible & 3.67 & 0.524 & & & \\
\hline
\end{tabular}

\section{Inherent dimensions of Egyptian food satisfaction: factor analysis}

Exploratory Factor Analysis (EFA) with Varimax rotation was undertaken on the data collected to pinpoint the dimensions of local food attributes' satisfaction (table 3). Kaiser-Meyer-Olkin (KMO) measure of sampling adequacy and the Bartlett's test of sphericity were measured to assess the factorability of the data, the KMO value at 0.873 exceeds the accepted minimum value which is 0.6 (Hair et al., 2006). The Bartlett's test of sphericity was found to be significant $(\mathrm{p}<0.00)$. Eigenvalue, scree plot, percentage of variance, item communalities and factor loadings were measured to determine the number of factors that will be derived, only factors with eigenvalue $\geq 1.0$ were considered, scree plots were also examined, items which had factor loadings lower than 0.4 or load at more than 0.3 on any other factor were eliminated.

Two factors have been identified explaining $53.44 \%$ of overall variance, the communalities of 10 attributes ranged from 0.323 to 0.691 . Cronbach's alpha score was measured to assess internal consistency between variables.

The two factors were named based on the items that loaded heavily on them: factor one with eight items related to "perceived quality \& accessibility" $(\alpha=0.871)$, factor two with two items is associated with "local food value and availability" $(\alpha=0.709)$.

According to the results of the mean scores of the two factors, it appears that factor two which relates to "local food value and availability" has a higher mean score at $\mathbf{3 . 8 5}$ compared to factor one "perceived quality \& accessibility" which has a mean score at 3.50. Specifically, tourists are more satisfied with food reasonable prices (03.95). However, they are less satisfied with food festivals (03.31) and preparation and cooking methods (03.37). 
Table (3): Exploratory Factor Analysis results for Egyptian food satisfaction.

Descriptive statistics, Cronbach's Alpha and factor loadings

\begin{tabular}{|c|c|c|c|c|c|}
\hline Dimensions & Mean & $\begin{array}{l}\text { Factor } \\
\text { Loadings }\end{array}$ & Eigen Value & $\begin{array}{l}\text { Variance } \\
\text { explained }\end{array}$ & Alpha \\
\hline $\begin{array}{l}\text { Perceived quality \& } \\
\text { accessibility }\end{array}$ & 3.50 & & 4.329 & 43.279 & 0.871 \\
\hline $\begin{array}{l}\text { I am satisfied with } \\
\text { varieties of restaurants }\end{array}$ & 3.57 & 0.766 & & & \\
\hline $\begin{array}{l}\text { I am satisfied with } \\
\text { Egypt's high quality food }\end{array}$ & 3.50 & 0.766 & & & \\
\hline $\begin{array}{l}\text { I am satisfied with food } \\
\text { experience }\end{array}$ & 3.66 & 0.750 & & & \\
\hline $\begin{array}{l}\text { I am satisfied with } \\
\text { methods of preparation } \\
\text { and cooking }\end{array}$ & 3.37 & 0.717 & & & \\
\hline $\begin{array}{l}\text { I am satisfied with } \\
\text { accessibility of places }\end{array}$ & 3.55 & 0.713 & & & \\
\hline $\begin{array}{l}\text { I am satisfied with } \\
\text { innovative dishes }\end{array}$ & 3.37 & 0.697 & & & \\
\hline $\begin{array}{l}\text { I am satisfied with food } \\
\text { festivals }\end{array}$ & 3.31 & 0.688 & & & \\
\hline $\begin{array}{l}\text { I am satisfied that } \\
\text { Egyptian food part of its } \\
\text { culture }\end{array}$ & 3.69 & 0.659 & & & \\
\hline $\begin{array}{l}\text { local food value and } \\
\text { availability }\end{array}$ & 3.85 & & 1.017 & 10.170 & 0.709 \\
\hline $\begin{array}{l}\text { I am satisfied with food } \\
\text { reasonable prices }\end{array}$ & 3.95 & 0.792 & & & \\
\hline $\begin{array}{l}\text { I am satisfied with local } \\
\text { food availability }\end{array}$ & 3.76 & 0.458 & & & \\
\hline
\end{tabular}

Perception of Egyptian food image and overall satisfaction with food experience 
Multiple regression analysis was used to estimate the coefficients of the multiple regression involving the three dimensions of the Egyptian cuisine images as independent variables that best predict the dependent variable "overall satisfaction". Table (4) highlights the results of using multiple regression. It is clear that "food environment" is an important food image that affects tourists' overall satisfaction with the highest beta value of $(0.373)$. Then the image of "Egyptian food attributes" (beta $=0.367$ ), whereas the image of "accessibility" affects slightly on overall satisfaction (beta $=0.147$ ). The results revealed that the model was significant and explained $55.8 \%$ of the variance in overall satisfaction $(\mathrm{F}=154.30, \mathrm{p}=0.00$. (Multiple $\mathrm{R}=0.747$ ) indicates high correlation between Egyptian food image and overall satisfaction.

Table (4) Results of multiple regression analysis of perception of Egyptian food image and overall satisfaction with food experience

\begin{tabular}{|c|c|c|c|c|}
\hline \multicolumn{2}{|l|}{ Variables } & $\begin{array}{r}\text { Standardized Coefficients } \\
\text { (Beta) }\end{array}$ & t-value & sig. \\
\hline \multirow{3}{*}{\multicolumn{2}{|c|}{$\begin{array}{l}\text { Egyptian food attributes } \\
\text { food environment } \\
\text { accessibility }\end{array}$}} & 0.367 & 7.53 & 0.00 \\
\hline & & 0.373 & 7.77 & 0.00 \\
\hline & & 0.147 & 3.92 & 0.00 \\
\hline Multiple R & 0.747 & & & \\
\hline $\mathrm{R}^{2}$ & 0.558 & & & \\
\hline Adjusted $\mathrm{R}^{2}$ & 0.554 & & & \\
\hline Standard error & 0.46 & & & \\
\hline $\mathrm{F}$ & 154.303 & & & \\
\hline
\end{tabular}

\section{Revisit intentions}

Cronbach's Alpha coefficient, $(\alpha=.810)$, was computed to assess the internal consistency reliability of the measure, which is above the suggested value of 0.7 (Nunnally and Bernstein, 1994).

The mean score of all the revisit intention items was $(\chi=3.47)$ as indicated in table (5) specifically, tourists would like to try other types of Egyptian food, which was reflected by the highest mean score $(\chi=3.88)$.

Table (5): revisit intentions

\begin{tabular}{l}
\hline Intentions \\
Mean \\
\hline revisit intentions \\
$\mathbf{3 . 4 7}$ \\
I may visit Egypt again for culinary tourism \\
3.20 \\
I would like to try other types of Egyptian food \\
\hline
\end{tabular}


3.88

I would recommend others to visit Egypt for culinary tourism

3.36

Overall. I have confidence in Egypt as a culinary destination

3.47

\section{Overall satisfaction with revisit intentions}

A simple linear regression analysis was performed to measure the independent effect of tourists' overall satisfaction with their food experience on their revisit intentions (table 6). The model was significant and explained $32 \%$ of the variance in revisit intentions ( $\mathrm{F}=172.50 \mathrm{p}=0.00$, Adjusted $\mathrm{R}^{2}=0.319$ ). The standardized beta coefficient was significant (beta $=0.564$ ) meaning that there is significant effect of tourists' overall satisfaction with their food experience on their revisit intentions, specifically tourists would like to try other types of Egyptian food.

Table (6): A simple linear regression analysis of overall satisfaction with revisit intentions

\begin{tabular}{|c|c|c|}
\hline \multicolumn{2}{|l|}{$\begin{array}{l}\text { Variables } \\
\text { t-value }\end{array}$} & $\begin{array}{l}\text { Standardized Coefficients } \\
\text { sig. } \\
\text { (Beta) }\end{array}$ \\
\hline \multirow{2}{*}{\multicolumn{2}{|c|}{$\begin{array}{l}\text { Overall satisfaction } \\
13.13\end{array}$}} & 0.564 \\
\hline & & 0.00 \\
\hline Multiple R & 0.564 & \\
\hline $\mathrm{R}^{2}$ & 0.32 & \\
\hline Adjusted $\mathrm{R}^{2}$ & 0.319 & \\
\hline Standard error & 0.65 & \\
\hline $\mathrm{F}$ & 172.50 & \\
\hline
\end{tabular}

\section{Discussion}

The purpose of this study was to provide a comprehensive knowledge and analysis of the current situation of culinary tourism in Egypt as regarded by international tourists. The study concluded that there is a relatively high acceptance among tourists that the construct "Egyptian food attributes" is a main image of the Egyptian food; particularly the friendly atmosphere, this result is quite congruous with the well-known friendliness nature of Egyptian people which was in turn reflected in its local food atmosphere. Good value for money is another apparent valued image of Egyptian food by tourists, while the diversity of information on local food was the less appreciated factor by tourists, it worth to note that there is absence of important information offered to tourists to be acquainted with the image of Egypt as a culinary destination. Egypt has quality, variety and regional diversity of foods, notably, olive oil, spices, fish and sea food, rice, vegetables, fruits, 
aromatic herbs, meat as well as a number of restaurants that serve traditional Egyptian cuisine. However, information regarding restaurants that offer local food, culinary schools, farms that produce unique local products, culinary events and festivals are not available, while it should be accessible to potential tourists preferably in official websites and different promotional materials offered by Ministry of Tourism.

Concerning dimensions of Egyptian food satisfaction, results revealed that satisfaction with the construct "local food value and availability" has a higher mean score compared to satisfaction with the construct "perceived quality \& accessibility" specifically satisfaction with local food price, we might consider this factor a key strength of Egyptian food attributes; The prices are quite reasonable and food is quite cheap by European standards. However, we should note that tourists were not satisfied enough with availability of food festivals and methods of preparation and cooking. It worth to mention that there are few organized culinary events and festivals in Egypt. Therefore, placing food events should be considered in developing different culinary products and activities in Egypt. One should note that little is known about these few food festivals held in Egypt that should be put into consideration while promoting culinary tourism in Egypt. Cairo Bites is one example in this concern; it is one of the biggest food festivals featuring a varied local, regional and international eating establishments and food-related businesses with entertaining program, cooking shows, food sampling and competitions by celebrity chefs. It is a relatively new established festival with over 100 participating restaurants and over 10,000 visitors of foodies. It is an annual festival held in April with the warmth of the spring weather, and the Bewitching nature that enhance visitors' experience. However, other food festivals and food fairs featuring local products should be developed and promoted.

Providing tourists with different culinary experiences through organizing visits to cooking schools located in different parts in Egypt where tourists are offered authentic dishes, gastronomic knowledge and cooking methods using varied and unique local products and create their own menus with authentic difference could enrich their culinary experiences. Adding cooking classes designed for children in this respect can create amazing memories and enhance their culinary experience.

Organizing visits to centers that host weekly farmers' markets could be another aspect of developing culinary activities in Egypt. These centers introduce most popular organic and healthy locally-grown vegetables, fruits and herbs on a weekly basis where visitors can have lunch and rest in nature as well.

The findings support the results of previous studies (Ab Karim et al., 2009; Peštek and C'injarevic, 2014) that local food image is one of the key 
determinants affecting tourist's food experience in a destination; study findings revealed that there is a high correlation between Egyptian food image and tourists' overall satisfaction, specifically the image of the construct "food environment" which has a considerable effect on tourists' overall satisfaction. This is consistent with the findings of a study conducted by Lin (2014) where he confirmed that DMOs should promote "comfortable and amiable environment" for better cuisine experience.

When assessing tourists revisit intentions, findings revealed that the item concerning "tourists would like to try other types of Egyptian food" has the highest mean score among other revisit intentions. It worth to mention in this respect that some tourists indicated that they will not return to Egypt just for culinary reasons mentioning that Egypt has more than food to offer to tourists who usually come to enjoy its unique historical and natural attractions. Perhaps Egypt's culture and rich history is not well-reflected in its food which may affect negatively on tourists intensions to return to taste its local food. This might be explained by Hjalager (2003) who mentioned that some tourists do not consider destination local food as the only factor that influences their travel experience. Hence, food experience does not contribute positively to return behavior. It could be argued then that providing other types of local food that reflect destination identity might increase tourists' satisfaction and motivate them to revisit the destination. In this respect, providing sufficient information concerning establishments featuring local cuisine should be a prime concern to provide tourists with opportunities to experience fabulous selection of Egyptian local food designed to delight a variety of tastes. We should also point to the importance of visiting restaurants whose offerings are introduced with a strong local basis that combine tradition and innovation.

\section{Conclusion}

Despite the importance of local food consumption on vacations, the research investigating perceived image of Egypt as a culinary destination among tourists is scarce. Unlike previous research which focused on Egypt's wellknown cultural heritage, this study encompasses unknown unique part of Egypt's history and culture that should be integrated as a complementary part of its unique cultural assets.

One of the most important theoretical contributions of the present study lies in exploring the most salient factors that contribute to the tourist's culinary experience with a clear focus on the local food context. Since Egyptian cuisine is highly marginalized in the tourism industry, the present study 
contributes to the limited literature on developing and promoting culinary tourism in Egypt.

This study provides detailed understanding of tourists' perceived image of Egypt's local food. It suggested a measurement scale that assesses main attributes of local food, and the effect of perceived image of local food on tourist satisfaction of their food experience and revisit intentions. This scale could be used and developed by other researchers for better understanding of how tourists view Egypt as a culinary destination.

The study has practical implications for the tourism industry in Egypt; it generates insights for managers, marketers and businesses to best develop and market their offerings based on analytical investigation of tourists' opinions and evaluations of various culinary dimensions related to their experiences. Therefore, tourists' experiences could be enhanced, overall perception of the destination and its competitiveness could be improved.

The potential growth of culinary tourism in Egypt will depend largely on raising awareness among international tourists of this sector who are not usually offered local food or other culinary activities during their visit. Therefore, Egypt is not well-recognized as a culinary destination to international tourists. Carrying out marketing activities, producing brochures and other promotional materials and including the culinary tourism in the official website of Ministry of Tourism as well as using social media to spread good word of mouth among tourists regarding culinary experiences in Egypt should be a prime concern.

It might be valuable also to include certain culinary activities during visiting programs, for instance, organizing traditional Egyptian nights where tourists are offered the opportunity to taste Egyptian food with a detailed description of each local dish, and at the same time present folkloric music and dancing that could enhance tourist's culinary experience and the perception of destination authenticity. Moreover, considerable attention should be given to organizing local food festivals in high season periods as this activity is highly marginalized in Egypt.

Visits to restaurants offering local food should be considered during visiting programs where guiding booklets and detailed menus illustrating ingredients of dishes are offered with a particular concern to place traditional settings where local food are prepared. Organizing visits to culinary schools where tourists can experience preparing local dishes themselves to enrich tourist's culinary experience should also be considered.

Despite the contributions of the findings, several limitations in this study should be mentioned. First, this study depends on previous studies to develop a measurement scale and extract main attributes affecting a destination's local food image, a qualitative research is required to integrate other factors considered by tourists themselves that affect their perception of a 
destination's local food. Second, this study focused only on demand-side to assess Egypt as a culinary destination, for more comprehensive assessment, future research should investigate the supply-side to identify Egypt's culinary resources and provide marketers with clearer guidelines for products that need to be developed.

It would be worthwhile for future research as well to investigate the proposed role of the tour guide in encouraging tourists to taste local food, telling hidden stories and ingredients of a destination's local food and linking it with its history, culture and traditions.

\section{References}

Ab Karim, S., Chua, B.L. and Salleh, H. (2009). Malaysia as a culinary tourism destination: International tourists' perspective, Journal of Tourism, Hospitality and Culinary Arts 1(3): pp. 63-78.

Chaney, S. and Ryan, C. (2012). Analyzing the evolution of Singapore's World Gourmet Summit: An example of gastronomic tourism, International Journal of Hospitality Management 31(2): pp. 309-318.

Chang, R., Kivela, J. and Mak, A. (2010). Food preferences of Chinese tourists. Annals of Tourism Research 37 (4): pp. 989-1011.

Cerovic, M. (2003),"Food marketing in the function of tourist product development", British Food Journal, 105(3): pp. $175-192$

Cohen, E. and Avieli, N. (2004). Food in tourism: attraction and impediment, Annals of Tourism Research 31(4): pp. 755-778.

El-Hamamsy, S. \& Pateman, R. (2003). Cultures of the World: Egypt, (2 ${ }^{\text {nd }}$ ed.), New York: Marshall Cavendish Benchmark

El-Hebeishy, M. (2010). Frommer's Egypt, New Jersey: Wiley Publishing

Frochot, I. (2003). An analysis of regional positioning and its associated food images in French tourism regional brochures. Journal of Travel and Tourism Marketing 14(3-4): pp. 77-96.

Hair, J., Black, B., Babin, R., Anderson, R., and Tatham, R. (2006). Multivariate data analysis $\left(6^{\text {th }}\right.$ ed.). New York: Prentice Hall.

Hall, C.M. and Mitchell, R. (2001). Wine and food tourism. In: N. Douglas, N. Douglas and R. Derrett (eds) Special Interest Tourism: Context and Cases. Brisbane, Australia: John Wiley \& Sons: pp. 307-329.

Hall, C.M. and Sharples, L. (2003). the consumption of experience or the experience of consumption? An introduction to the tourism of taste. In: Hall, C.M., Sharples, L., Mitchell, R., Macionis, N., and Cambourne, B. (eds) Food Tourism Around the World: Development, Management and Markets. Oxford, Uk: Butterworth-Heinemann, 1-24. 
Hall, C. M. and Mitchell, R. (2005). Gastronomic Tourism: Comparing Food and Wine Tourism Experiences, In: M. Novelli (ed.) Niche Tourism: Contemporary Issues, Trends and Cases. Oxford: Butterworth: pp. 73-88.

Hjalager, A. M. and Richards, G. (eds.) (2002). Tourism and Gastronomy. London: Routledge.

Horng, J. S., and Hu, M. L. (2009) The effect of creative culinary process to creative culinary performance. Journal of Hospitality, Leisure, Sport and Tourism Education, 8(2): pp. 34-46.

Horng, J. S. and Tsai, C. Y. (2010). Government websites for promoting East Asian culinary tourism: A cross national analysis. Tourism Management, 31: pp. 74-85.

Horng, J. S. and Tsai, C. Y. (2012). Culinary Tourism Strategic Development: an Asia-Pacific Perspective, International Journal of Tourism Research 14: pp. 40-55.

Horng, J. S., Liu, C.H., Chou, H. Y. and Tsai, C.Y.(2012). Understanding the impact of culinary brand equity and destination familiarity on travel intentions, Tourism Management 33: pp. 815-824.

Hosking, R. (2006). Authenticity in the Kitchen. In: Proceedings of the Oxford Symposium on Food and Cookery 2005, Devon: Prospect Books.

Ignatov, E. and Smith, S. (2006). Segmenting Canadian culinary tourists, Current Issues in Tourism 9(3): pp. 235-255.

Jalis, M., Che, D. and Markwell, K.(2014). Utilising local cuisine to market Malaysia as a tourist destination, Procedia - Social and Behavioral Sciences 144: pp. $102-110$

Kim, Y., Eves, A. and Scarles, C. (2009). Building a model of local food consumption on trips and holidays: A grounded theory approach, International Journal of Hospitality Management 28: pp. 423-431.

Kim, Y. and Eves, A. (2012). Construction and validation of a scale to measure tourist motivation to consume local food, Tourism Management 33: pp. 1458-1467.

Kim, Y., Eves, A. and Scarles, C. (2013) Empirical verification of a conceptual model of local food consumption at a tourist destination, International Journal of Hospitality Management 33: pp. 484-489.

Kivela, J. and Crotts, J. C. (2006). Tourism and gastronomy: gastronomy's influence on how tourists experience a destination, Journal of Hospitality and Tourism Research 30(3): pp. 354-377.

Kivela, J. and Crotts, J. C. (2009). Understanding Travelers' experiences of gastronomy through Etymology and Narration, Journal of Hospitality \& Tourism Research 33(2): pp. 161-192.

López-Guzmán, T. and Sánchez-Cañizares, S. (2012). Culinary tourism in (Spain Córdoba), British Food Journal 114 (2): pp. 168 - 179. 
Lin, Y. C. (2009). Linking Local and Culinary Cuisines with Destination Branding, In: Cai, L., Gartner, W. and Munar, A. (eds.) Tourism Branding: Communities in Action (Bridging Tourism Theory and Practice, Volume 1), Bingley, Uk: Emerald Group Publishing Limited: pp. 105 - 118.

Lin, Y. C., Pearson, T. and Cai. L. (2011). Food as a form of Destination Identity: A Tourism Destination Brand Perspective, Tourism and Hospitality Research 11 (1): pp. 30-48.

Lin, C. H. (2014). Effects of Cuisine Experience, Psychological Well-Being, and Self-Health Perception on the Revisit Intention of Hot Springs Tourists, Journal of Hospitality \& Tourism Research 38 (2): pp. 243-265.

Long, L. M. (2004). Culinary Tourism. Kentucky: The University Press of Kentucky.

Mak, R., Blose, J. and MacLauren, T. (2009). Segmenting the culinary tourist market: an American and Australian comparison. In: Proceedings of the 2009 Oxford Business \& Economics Conference Program. June 24-26 2009. St. Hugh's college, Oxford, UK: Oxford University.

Mak, A., Lumbers, M. and Eves, A. (2012a). Globalization and Food Consumption in Tourism, Annals of Tourism Research 39(1): pp. 171-196.

Mak, A., Lumbers, M., Eves, A. and Chang, R. (2012b). Factors influencing tourist food consumption, International Journal of Hospitality Management 31: pp. 928-936.

Mason, M. and Paggiaro, A. (2012) .Investigating the role of festivalscape in culinary tourism: The case of food and wine events, Tourism Management 33: pp. 1329-1336.

Mkono, M. (2011). The othering of food in touristic entertainment: A netnography, Tourist Studies, 11(3): pp. 253-270.

Molz, J. (2007). Eating Difference: The Cosmopolitan Mobilities of Culinary Tourism, Space and Culture 10 (1): pp. 77-93

Nunnally, J. C. and Bernstein, I.H. (1994). Psychometric Theory ( $3^{\text {rd }}$ ed.). New York: McGrow-Hill.

Obonyo, G., Ayieko, M. and Kambona, O. (2012). An importance-performance analysis of food service attributes in gastro-tourism development in Western Tourist Circuit, Kenya, Tourism and Hospitality Research 12 (4): pp. 188200.

Ottenbacher, M. and Harrington, R. (2013). A case study of a culinary tourism campaign in Germany: implications for strategy making and successful implementation, Journal of Hospitality \& Tourism Research 37 (1): pp. 328. 
Pes tek, A. and C`injarevic, M. (2014). Tourist perceived image of local cuisine: the case of Bosnian food culture, British Food Journal 116 (11): pp. 1821 1838.

Rishi, I. (2012). Super Snacks: 100 Favourite Snacks from Five Continents, Trafford Publishing

Robinson, R. and Getz, D., (2014) Profiling potential food tourists: an Australian study, British Food Journal 116 (4): pp.690 - 706.

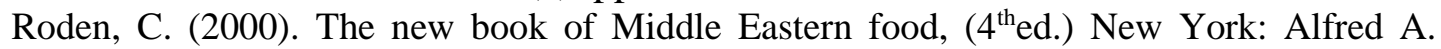
Knopf.

Sanchez-Cañizares, S. and Castillo-Canalejo, A. (2015),"A comparative study of tourist attitudes towards culinary tourism in Spain and Slovenia", British Food Journal, 117(9): 2387 - 2411

Sotiriadis, M. (2015),"Culinary tourism assets and events: suggesting a strategic planning tool", International Journal of Contemporary Hospitality Management, 27(6): pp.1214 - 1232

Smith, S. and Xiao, H. (2008). Culinary tourism supply chains: a preliminary examination, Journal of Travel Research 46: pp. 289-299.

Smith, S. and Costello, C. (2009). Culinary tourism: Satisfaction with a culinary event utilizing importance-performance grid analysis, Journal of Vacation Marketing 15 (2): pp. 99-110.

Sparks, B. (2007). Planning a wine tourism vacation? Factors that help to predict tourist behavioural intentions, Tourism Management 28: pp.1180-1192.

Surenkok, A., Baggio, R. and Corigliano, M. (2010). Gastronomy and Tourism in Turkey: The Role of ICTs. In: Information and Communication Technologies in Tourism2010, Proceedings of the International Conference in Lugano, Switzerland, February 10-12 2010. Vienna: Springer 567-578.

Updhyay Y and Sharma D (2014). Culinary preferences of foreign tourists in India. Journal of Vacation Marketing 20(1): pp.29-39.

Wilson, H. (1988). Egyptian Food and Drink, Buckinghamshire: SHIRE PUBLICATIONS.

Wolf, E., Bussell, J., Campbell, C., McAree, K. and Faria, W. (eds.) (2014). Have Fork Will Travel: A Practical Handbook for Food and Drink Tourism Professionals, Oregon: World Food Travel Association.

World Tourism Organization (2012). Global report on food tourism. Madrid: UNWTO.

Yuan, E. (2013) Who are the culinary tourists? An observation at a food and wine festival, International Journal of Culture, Tourism and Hospitality Research 7(2): pp. $118-131$.

Yun, D., Hennessey, S.M. and MacDonald, R. (2011) Understanding Culinary Tourists: Segmentations based on Past Culinary Experiences and Attitudes toward Food-related Behaviour, In: International CHRIE Conference-Refereed Track, Denver, Colorado, USA, 27-30 July, 2011, Available at:http://scholarworks.umass.edu/refereed/ICHRIE_2011/Friday/15 (accessed on:10 April 2015). 